\title{
A New Breeding Technique for Increasing Genetic Differences Between Parents and Enhancing Hetero Sis
}

\author{
Zhanliang Yang ${ }^{1}$, Qiaoxu Chu ${ }^{2}$, Longjuan You ${ }^{1}$, Runhong Zeng ${ }^{3}$, Yile Zhang ${ }^{4}$, Zhou Yang ${ }^{1}$, \\ Guobin Wang, ${ }^{\text {, * }}$
}

${ }^{1}$ Ba Yi Middle School, Longnan, China

${ }^{2} \mathrm{Wu}$ Du Bin Jiang Middle School, Longnan, China

${ }^{3} \mathrm{Wu}$ Du Cheng Guan Middle School, Longnan, China

${ }^{4}$ China Longnan Wudu First People's Hospital, Longnan, China

${ }^{5}$ China Longnan Wudu Pepper Center, Longnan, China

\author{
Email address: \\ 823576619@qq.com (Guobin Wang) \\ ${ }^{*}$ Communication author
}

\section{To cite this article:}

Zhanliang Yang, Qiaoxu Chu, Longjuan You, Runhong Zeng, Yile Zhang, Zhou Yang, Guobin Wang. A New Breeding Technique for Increasing Genetic Differences Between Parents and Enhancing Hetero Sis. International Journal of Applied Agricultural Sciences. Vol. 5, No. 2, 2019, pp. 56-61. doi: 10.11648/j.ijaas.20190502.15

Received: January 28, 2019; Accepted: April 4, 2019; Published: June 12, 2019

\begin{abstract}
In order to find a new technique for breeding super high varieties of wheat s, according to the theory that rare gene activity will be caused then make new genotypes, and promote branch and evolution of species in strange radiation fields, and the principle of mutagenic breeding, In order to increase crop yield, it is necessary to improve the physiological metabolic intensity of plants and improve the hybridization advantages in breeding. In order to improve the hetero sis of hybrids, there must be large genetic differences between parents and close to extreme types as far as possible. However, for crops with little genetic difference among wheat and other varieties, it is difficult to develop new varieties with high yield by conventional hybrid breeding. Therefore, by means of radiation mutagenesis, one or two parents of the hybrid can be mutated, which can improve the genetic difference between the parents and enhance the hetero sis of the hybrid parents. For this, we call it "new technology". In this paper, the technology of breeding high varieties directly in progeny with various radiation factors and of $\mathrm{F}_{0}, \mathrm{~F}_{1}, \mathrm{~F}_{3}$ by irradiation is called "classical technique." By comparing "new technology" with "classical technology", this paper introduces the practice and application prospect of the new technology, and introduces the characters, advantages and disadvantages and application value of the super-large grain wheat variety "Long Nan 71a" cultivated by the new technology.
\end{abstract}

Keywords: New Technology, Radiation Mutagenesis, Genetic Difference, Abnormal Mutation, Super-Large Grain

\section{Introduction}

Breeding high-yield and super-high-yielding crop varieties is the dream and lifelong pursuit of breeders. As a result, breeders developed a variety of mature and reliable breeding techniques, and successfully cultivated many good varieties, which greatly increased crop yield.

Scientists have successfully selected many famous varieties by space breeding, ion beam implantation, radiation. The most exciting technology of Yuan Long ping hybrid rice made rice yield per mu exceeded the $1000 \mathrm{~kg}$ mark. However, wheat, as the second largest crop in the world and the staple food of more than half of the population, has been in a slow climbing stage for more than ten years. [1] The main reason is that the range of available excellent germ plasm resources has been very narrow, and all kinds of e Genetic differences between different varieties are small, [2] not two extreme types. Conventional hybrid breeding has made most of the high-yielding genes concentrated in high-yielding parents, which makes the utilization of hetero sis difficult. The basic reason for the formation of hetero bsis lies in the genetic difference between parents, [3] As a result, the hybrid advantage between wheat varieties is limited and it is difficult to obtain the same hybrid advantage and ultra-high 
yield as hybrid rice. Using the combination of space breeding, ion beam injection, radiation mutagenesis, radiation mutagenesis and hybridization, scientists have successfully cultivated many famous varieties. [4-7] Zhou mai 27, bred by Henan experts, set a record of $821.7 \mathrm{~kg}$ per mu in Jiaozuo Xiu Wu County in 2016.However, there is still a certain gap between its yield per Mu and that of hybrid rice.

It was envisaged by the writer that genetic differences and metabolic intensity differences would be induced in different structural radiation fields for varieties with small genetic differences, such as the floral apparatus of wheat with different spectra of light treatment that entered the reproductive state. However, these assumptions are not easy to implement and can only be indirectly verified using frog fertilized eggs as experimental materials under monochromatic light. [8] We believe that radiation fields with special structures can induce special gene mutations. In the very special structure of the radiation field, rare genetic activity can be induced to produce new genotypes, which will promote the branching and evolution of species. [9] In order to increase wheat yield, we must first increase the physiological metabolic strength of crops, increase the genetic difference of hybridization combinations, and reduce the hybridization combinations of homologous repulsion of molecules. [10] Wei bo Han and others believe that mutagenic breeding plays a unique role in crop variety improvement. It can induce gene mutation and produce new types, new traits and new genes that are not previously available in nature or difficult to obtain by conventional methods. It can break the linkage of gene and increase the rate of recombination. [11].

Therefore, we suggest that an effective way to increase genetic differences between parents is to artificially induce mutations (or use different mutative factors such as radiation, chemistry, space, particle beams, etc.) and mutate them. After the mutation, the genetic difference between the mutant plant genotype and the normal plant increased, and the hybrid offspring may have strong hetero sis. We call it "new technology". The predecessors used various radiation factors to treat crop seeds, and directly selected excellent varieties from the offspring, or radiation hybrids $\mathrm{f} 0, \mathrm{~F} 1, \mathrm{~F} 3$, etc., and selected excellent varieties from the offspring, which was called "classic technology." Table 1 shows the comparison between "new technology" and "classic technology"

Table 1. Comparison of "Classic Technology" and "New Technology".

\begin{tabular}{|c|c|c|c|}
\hline & Classic technology & & New technique \\
\hline $\begin{array}{l}\text { Technical } \\
\text { route }\end{array}$ & $\begin{array}{l}\text { Crop seeds were treated with } \mathrm{X} \text { ray, } \\
60 \mathrm{Co} \gamma \text { ray, space environment, ion } \\
\text { beam implantation and so on. } \\
\text { Directly breed fine varieties from } \\
\text { irradiated seeds and offspring. }\end{array}$ & $\begin{array}{l}\text { Wheat hybrid } \mathrm{F}_{0}, \mathrm{~F}_{1}, \mathrm{~F}_{3} \text { was } \\
\text { irradiated by } 60 \mathrm{Co} \gamma \text {-ray and the } \\
\text { fine varieties were selected from } \\
\text { the progenies of mutagenic } \\
\text { hybridization. }\end{array}$ & $\begin{array}{l}\text { One of the parents of the wheat hybridization is treated } \\
\text { with high-energy X-rays and nuclear magnetic resonance } \\
\text { (or other radiation factor mutagenesis), and then undergom } \\
\text { ultiple generations of mutagenesis until the malformed } \\
\text { mutant plants appear and hybridize with the target parent. } \\
\text { Choose the best strains from the next generation. }\end{array}$ \\
\hline $\begin{array}{l}\text { Theoretical } \\
\text { basis }\end{array}$ & $\begin{array}{l}\text { High-energy radiation can cause } \\
\text { damage to DNA molecules, trigger } \\
\text { genetic mutations, and produce new } \\
\text { genotypes and new varieties }\end{array}$ & $\begin{array}{l}\text { Compared with cultivars, hybrid } \\
\text { species have higher radiation } \\
\text { sensitivity. The combination of } \\
\text { radiation and hybridization can } \\
\text { effectively improve the effect of } \\
\text { radiation breeding. }\end{array}$ & $\begin{array}{l}\text { After the radiation-induced gene mutation, the mutant plant } \\
\text { was malformed. There is a large genetic difference between } \\
\text { these malformed mutant plants and the target parent. After } \\
\text { hybridization, there may be a strong hybridization } \\
\text { advantage }\end{array}$ \\
\hline $\begin{array}{l}\text { Achievements } \\
\text { and prospects }\end{array}$ & $\begin{array}{l}\text { Using radiation mutagenesis } \\
\text { technology, a large number of } \\
\text { excellent varieties have been } \\
\text { cultivated, and there are still broad } \\
\text { application prospects. }\end{array}$ & $\begin{array}{l}\text { Many excellent varieties have } \\
\text { been cultivated, and the } \\
\text { technology has broad application } \\
\text { prospects. }\end{array}$ & $\begin{array}{l}\text { With this technology, a new wheat variety with the largest } \\
\text { seed size has been cultivated. The technical route is not yet } \\
\text { mature, and the application prospects are broad. Can be } \\
\text { used for breeding of all crop varieties. }\end{array}$ \\
\hline References & (7), (11).etc. & $(5),(6),(7),(11)$. etc. & $(9),(10),(12),(14)$ \\
\hline
\end{tabular}

\section{Method}

More than ten kinds of wheat materials collected from the wild are treated with medical instruments. From 2003 to 2009 , the radiation and control team used X-rays or highenergy X-rays for "radiation treatment", high-energy X-rays for "radiation treatment", plus nuclear magnetic resonance group 3 processing. [11] And. There was no strict comparative analysis of the three groups of radiation treatments, only repeated treatment of these materials over the years until the deformed mutant wheat plants visible on the macroscopic phenotype were observed.

\section{Result}

In 2007, various types of malformed mutant plants appeared in the mutagenesis group. The typical malformed mutant plants were used as parents to cross with the fine wheat plants growing in the field. The hybridization effect of malformed mutant plants with normal plants was observed. [11] See table 2.

Table 2. Effect of physical factory-induced hybridization of malformed wheat plants with normal plants.

\begin{tabular}{llll}
\hline Organ & Type of malformed mutation & Genetic status & The performance of hybrid offspring \\
\hline $\begin{array}{l}\text { Wheat } \\
\text { Leaf }\end{array}$ & $\begin{array}{l}\text { Leaf surface twisted, half atrophied, } \\
\text { half yellow }\end{array}$ & $\begin{array}{l}\text { The next generation of sowing seldom produces } \\
\text { the same kind of distortion. }\end{array}$ & No significant advantage \\
\hline
\end{tabular}




\begin{tabular}{|c|c|c|c|}
\hline Organ & Type of malformed mutation & Genetic status & The performance of hybrid offspring \\
\hline $\begin{array}{l}\text { Wheat } \\
\text { stalks }\end{array}$ & $\begin{array}{l}\text { High stem, low stem, very short stem } \\
\text { only } 20 \mathrm{~cm} \text {, slightly twisted under the } \\
\text { stem of wheat spike, G-shaped } \\
\text { curvature occurs at only one node per } \\
\text { plant. }\end{array}$ & $\begin{array}{l}\text { In the next generation of sowing, there are fewer } \\
\text { mutations of the same type of deformity. Plants } \\
\text { with very short stems exhibit a genetic } \\
\text { disadvantage. }\end{array}$ & $\begin{array}{l}\text { There is no significant advantage, low dwarf } \\
\text { stem hybridization } F 1 \text { shows disadvantage. }\end{array}$ \\
\hline $\begin{array}{l}\text { Ear of } \\
\text { wheat }\end{array}$ & $\begin{array}{l}\text { The flag leaf wraps the wheat ear type, } \\
\text { the wheat ear distorts } 90 \text { degrees at the } \\
\text { flag leaf, the wheat ear automatically } \\
\text { distorts } 180 \text { degrees at the flag leaf, and } \\
\text { the wheat ear is automatically twisted } \\
\text { inside the flag leaf. }\end{array}$ & $\begin{array}{l}\text { The type that makes the flag leaf wrap the ear of } \\
\text { wheat is more of the same type in the next } \\
\text { generation. The ear of wheat turns } 90 \text { degrees } \\
\text { and } 180 \text { degrees, and the next generation } \\
\text { becomes another type. }\end{array}$ & $\begin{array}{l}\text { After hybridization with normal } \\
\text { hybridization parents, F1 showed a strong } \\
\text { advantage. In F2, F3 and F4, there are large } \\
\text { wheat ears and oversized wheat seeds, and } \\
\text { twisted spiral-shaped wheat ears continue to } \\
\text { appear in offspring (see figures } 3 \text { ). }\end{array}$ \\
\hline Flower & $\begin{array}{l}\text { Three male sterile plants without pollen } \\
\text { in male flowers were observed. }\end{array}$ & & $\begin{array}{l}\text { After artificial pollination, seeds were } \\
\text { produced, but F1 had no significant } \\
\text { advantage. }\end{array}$ \\
\hline $\begin{array}{l}\text { Wheat } \\
\text { seeds }\end{array}$ & Large grain traits observed from 2008 & $\begin{array}{l}\text { The heredity of large grain traits is relatively } \\
\text { stable. }\end{array}$ & $\begin{array}{l}\text { After crossing with Lovrin, F1 showing } \\
\text { strong superiority of a grain length of } 8 \mathrm{~mm} \\
\text { and a kilo-grain weight up to } 80 \mathrm{~g}, \mathrm{~F} 2 \\
\text { showing character segregation }\end{array}$ \\
\hline
\end{tabular}

The natural mutant material 2003B was treated for 5 times, and the character of large grain appeared in 2008, and in 2009 , the character of large grain was obvious, that is, No. 09-3 (Figure 1). 09-3 × Lovrin, F1 showed super strong hetero sis with grain length of $8 \mathrm{~mm}$ and 1000 -grain weight of 80g. After F2, traits were segregated. In 09-3, the mutant plant of wheat panicle torsion 90 degrees was found (see Figure 1). [12] The next generation of this material is used as the mother of hybridization, and Mian yang 36 is used as the father of hybridization. The F1 shows a strong advantage, calling it 2010-4. Among them, the performance of 2010-11 is also outstanding. In their own offspring, there are helical malformed mutant plants in the ear of wheat (Figure 3).

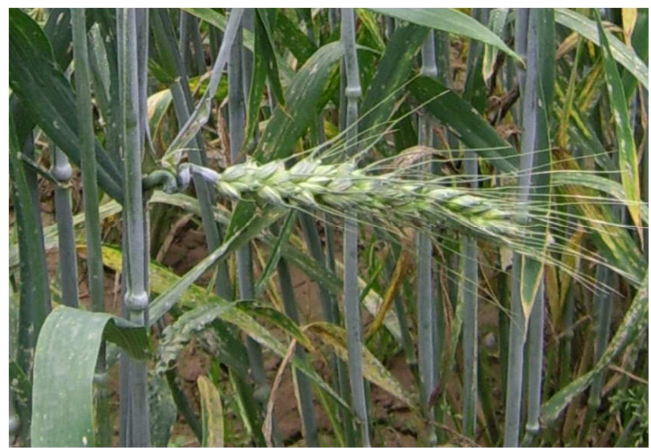

Figure 1. $90^{\circ}$ curved aberrant plants in 09-3.

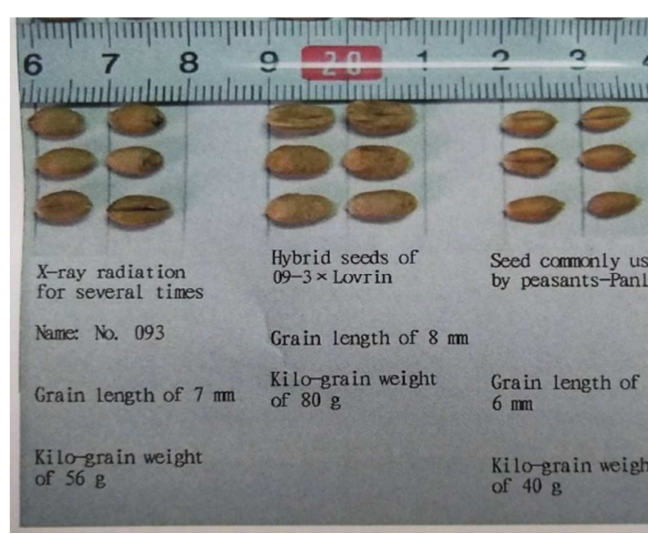

Figure 2. Mutagenic and hybrid large-grain wheat.

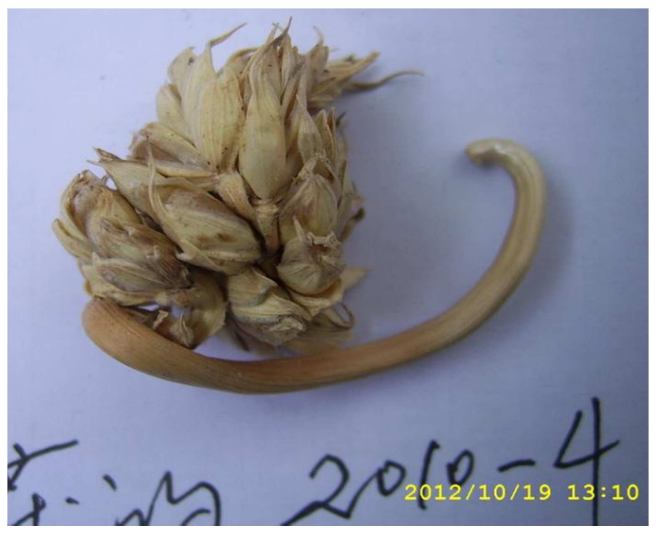

Figure 3. Mutagenic and hybrid-occurring spiral-distorted wheat ear.

There must be a variety of aberrations in the progeny of the spiral disc curl of wheat spike. These aberrant plants and combinations with them are like the kaleidoscope that opens the mutation. Among them are high stems, middle stems, and short stems. There are also large grain wheat plants. In 2014, the maximum 1000-grain weight was $73.0 \mathrm{~g}, 77.0 \mathrm{~g}, 80.0 \mathrm{~g}$ and $84.8 \mathrm{~g}$, respectively. Materials with a maximum 1000grain weight of 84.8 grams were obtained

From the F 4 generation 2010-4, which marked as "Long Nan 71a", the maximum grain number per spike was 120 grains, including 103 grains per plant and $8.3 \mathrm{~g}$ dry weight per ear. When potassium dihyd ro gen phosphate was sprayed during breeding in 2016, 1000 kern el weight and grain size increased. From three years of continuous seeding experiment from 2014 to 2016, it was found that the characteristics of "super-large grain" in Long Nan 71a were stable. A lot of aberrant plants appeared in Longnan71a breeding community, and a large number of variants appeared in a community near the canal. It can be seen that Long Nan 71a is expected to be further selected as a superhigh-yielding variety. Especially there are some single plants with other characteristics of the disease resistance, early maturing, big spike, large grain, early maturing among them.

The "Long Nan 71a", an oversized grain of wheat selected using this new technology, has the characteristics of ultra- 
high-yield wheat. The defect is that the plant height is 100 $120 \mathrm{~cm}$, the head weight is heavy but the root is light, so the lodging resistance is poor. In order to reduce the height of the plant and to enhance the anti-reversion, we used the "Long Nan 71a" strain and the normal strain in 2016 to carry out positive and negative hybridization with other dwarfing varieties, and then made seven hybrid combinations. Three of the combined $\mathrm{F}_{0}$ seeds were very thin, worried about the emergence of the seedlings, soaking the seedlings with a paper towel, and transplanting the seedlings in the flower pot more than 40 days earlier than the normal sowing time. In the area of $\mathrm{Wu}$ du area with less rainfall and more sunny days, the other five combined species are in the Cheng Xian county experimental field with more rainfall and less sunny day. Among them, combination No. 3 (12 dwarf flag leaf panicle plant X 71a) is planted in both two places. In this paper, the characters of F1 were observed in 2017 and compared with the two field varieties. See Table 3.

From Table 3, it can be seen that both male and female parents cross in Long nan 71a, F1 has the characteristics of super-large grains, the characteristics of super-large grains have the trend of dominant characters, and the height of plants has decreased. "X71a" of No. 3 dwarf flag leaf panicle plant showed great difference in two different grow the environments, and it was inferred that the latter four combinations would also show greater superiority in normal growth environment. In hybrid group, the grain size and grain weight were significantly different between Long Nan 71a and Pan Lin.

Table 3. Comparison of $F 1$ and two field cultivars using new germ pl as $m$ wheat for hybridization in 2016.

\begin{tabular}{|c|c|c|c|c|}
\hline & Rowth conditions & $\begin{array}{l}\text { Plant } \\
\text { height }(\mathrm{cm})\end{array}$ & $\begin{array}{l}\text { spike length } \\
\text { (cm) }\end{array}$ & $\begin{array}{l}\text { Number of seeds } \\
\text { per ear of wheat }\end{array}$ \\
\hline 71a-Dwarf stem mutants X 1a-Very short stem mutant & The wheat in the flower pot in Wud & $70-93$ & $12-15$ & 77 \\
\hline 71a X 1a1a Very short stem mutant & Du District has a higher temperature & $70-98$ & $11-16$ & 76 \\
\hline No.12 dwarf flag leaf panicle plant X 71a & $\begin{array}{l}\text { and less rainy season. Planting } 45 \\
\text { days in advance. }\end{array}$ & $65-80$ & $10-15$ & 54 \\
\hline No.12 dwarf flag leaf panicle plant X 71a & & $80-95$ & $10-12$ & 80 \\
\hline No. $31 \times 71 \mathrm{a}$ & Cheng Xian wheat. Sowing time: $24-$ & $80-105$ & $10-13.5$ & 84 \\
\hline $\begin{array}{l}\text { 64CMalformedmutation } X \\
\text { No.12 dwarf flag leaf panicle plant }\end{array}$ & $\begin{array}{l}\text { rainfall during grouting and } \\
\text { maturation, with maximum sunshine }\end{array}$ & $85-115$ & $10-13$ & 94 \\
\hline 71a X No.12 dwarf flag leaf panicle plant & of two days per week starting on 10 & $80-100$ & $10-12.5$ & 96 \\
\hline $71 \mathrm{a}$ & May 2017week & $100-130$ & $10-13$ & 69 \\
\hline PanLin & & $100-120$ & $9-12$ & 86 \\
\hline
\end{tabular}

Table 3. Continued.

\begin{tabular}{|c|c|c|c|c|c|}
\hline & $\begin{array}{l}\text { Single spike } \\
\text { weight (g) }\end{array}$ & $\begin{array}{l}\text { 1000-grain } \\
\text { weight (g) }\end{array}$ & $\begin{array}{l}\text { Maximum } \\
\text { grain lengt } \\
(\mathrm{mm})\end{array}$ & $\begin{array}{l}\text { Maximum } \\
\text { grain width } \\
(\mathrm{mm})\end{array}$ & $\begin{array}{l}\text { Thickness of } \\
\text { maximum } \\
\text { particles }(\mathrm{mm})\end{array}$ \\
\hline 71a-Dwarf stem mutants X 1a-Very short stem mutant & 4.80 & 62.3 & 9.0 & 4.0 & 3.0 \\
\hline 71a X 1a1a Very short stem mutant & 5.20 & 68.4 & 8.8 & 4.6 & 3.6 \\
\hline No.12 dwarf flag leaf panicle plant X 71a & 3.68 & 68.1 & 9.0 & 4.3 & 3.5 \\
\hline No.12 dwarf flag leaf panicle plant X 71a & 4.10 & 51.3 & 8.3 & 3.9 & 3.5 \\
\hline No. $31 \times 71 \mathrm{a}$ & 5.00 & 59.5 & 8.5 & 4.0 & 3.6 \\
\hline 10a-Malformed mutation X 71a & 4.20 & 51.2 & 7.8 & 3.8 & 3.2 \\
\hline $\begin{array}{l}\text { 64CMalformedmutation X } \\
\text { No.12 dwarf flag leaf panicle plant }\end{array}$ & 4.45 & 47.8 & 7.6 & 3.9 & 3.3 \\
\hline 71a X No.12 dwarf flag leaf panicle plant & 4.55 & 47.4 & 8.3 & 4.0 & 3.4 \\
\hline $71 \mathrm{a}$ & 4.40 & 63.2 & 8.8 & 4.5 & 3.8 \\
\hline PanLin & 3.50 & 40.6 & 7.3 & 3.6 & 2.9 \\
\hline
\end{tabular}

\section{Discuss}

\subsection{Science and Feasibility of New Technology}

The idea of this study is a mature and reliable scientific theory, proposed by the predecessors, [4-7, 11] plus your own ideas $[8,9,12,13]$ There are also many studies on the use of mutagenesis and hybridization techniques to cultivate wheat varieties. These excellent research work has successfully cultivated many excellent varieties and made outstanding contributions to the breeding industry in China. The difference is that the previous method combined mutation and hybridization is hybrid seed contemporary (f0), and hybrid seed offspring F1, F3. [6] Do radiation to increase mutation effect [5] These methods are first conventional hybridization and then radiation mutation. Its main purpose is to use sensitive types and sensitive periods to increase mutagenic effects. Those efforts have proved to be effective. Our job is to do the wheat first with radiation mutagenesis. The mutant is then hybridized with another normal wheat. Its main purpose is to use mutations to change the genotype of hybridized parents, increase genetic differences between parents, and thus enhance hetero sis. In fact, some predecessors have applied useful mutations of radiation mutagenesis to hybrid breeding, but the results have not been 
reported and discussed in detail. Therefore, we called the use of radiation mutagenesis to produce abnormal mutants and normal parents to cross breeding technology "new technology" which will first mutagenic, then cross, this new technology is carried out on the basis of previous work and has its scientific basis. Its equipment is simple; the operation process is easy to carry out.

\subsection{Problems in the Process of Research}

In the early stages of radiation mutation, X-rays are used to illuminate seeds, and the mutation effect is poor. Highenergy X-ray radiation and nuclear magnetic resonance twofactor treatment are then used. The single factors of highenergy X-ray radiation, "high-energy X-ray radiation-nuclear magnetic resonance", nuclear magnetic resonance single factors and control group were designed. However, these three groups of treatments have not been carefully compared and analyzed, nor have they detected the different effects of the three groups of treatments (strictly speaking, the three groups of treatments have different effects). Instead, the material is irradiated repeatedly year after year until abnormal mutations in the macroscopic phenotype occur. In fact, as long as the appropriate dose can induce gene mutation, sometimes mutations have taken place at the molecular level, but not at the macro level. At the biological stage of the radiation effect, the time can be from a few seconds to several years, on the basis of the change of molecular structure, the biochemical process of the cell changes, resulting in profound changes in the structure of various organelles and their components, Including chromosome aberration and gene mutation. [14] In general, gene mutations are harmful to the survival of individuals, but in rare cases, beneficial mutations can be produced. The teratogenic mutation has a direct effect on the survival ability of animals. For plants, the survival ability is greater as long as it is not albino seedlings. As long as the phenotype is abnormal, there is a big genetic difference between the mutant and the original variety, and crossing with the normal plant may lead to strong heterosis. In order to survive, reverse mutations in mutations may occur in M1 or M2 and subsequent generations. In the process of restoring mutations, some gene recombination may occur. In plants with normal phenotypes, some new genotypes may be different from the original genotypes, and some may completely return to the original genotype. Therefore, mutant individuals used for hybridization have the best effect in selecting plants with contemporary malformation mutations, especially plants with coiled wheat spikes. Although surgery is very difficult due to malformations, the effect of hybrid breeding is strange. of. The reproductive offspring of malformed mutants, used for hybridization, also have good results. But it extends the age of selection and reduces efficiency.

\subsection{The Breeding Value of Wheat Material with Oversized Grain}

We have developed many wheat germplasm materials using the "new technology", the most valuable of which is "71a". In 2015, the highest 1,000 grains weighed 84.8 grams, the average 1,000 grains weighed 61.5 grams, and the maximum number of grains per ear was 106 . The maximum grain weight per spike is 8.3 grams. It has the characteristics of ultra-high yield varieties. The plant height is about 80 $120 \mathrm{~cm}$, and the spike is big, the head is heavy but the root is light, so the ability to resist lodging is poor. Therefore, it does not have the characteristics of fine varieties. However, the super-large grain character of this germplasm can be inherited stably. Among the three factors of yield composition, the genetic ability of seed particles is the largest and most stable, and their yield traits are least affected by the environment. [15] There are still some mutants in Longnan 71a, among which there are low rod type, but the characteristics of Super-large grain grains remain stable, which is consistent with the literature, that is, using the medium stem and low stem type of the variant, the lodging resistant varieties may be selected. In 2016, we used 71a as the mother and hybridized with wheat with a plant height of $40 \mathrm{~cm}$, The Super-large grain of F1 can stabilize inheritance, and the resistance to lodging could be obtained by using the medium stem and low stem type of the variant, Therefore, it is possible to select low stalk lodging resistant varieties after generation. Among $\mathrm{F}_{2}$ generation sowed in 2018 , there was a large separation. Among these segregated progenies, some dwarf individuals with plant height of less than $70 \mathrm{~cm}$ and 1000 -grain weight of more than $60 \mathrm{~g}$ were found, as well as some disease-resistant individuals.

\section{Conclusion}

A new breeding technique is proposed, which is a plant that uses physical or chemical means to mutate crops and select malformed mutations in offspring. These abnormal mutations mean that gene mutations have occurred, which are very different and different from normal plant genes. This is the basis for improving the Hybridization advantage. A strong hybridization advantage can be formed by hybridization of these malformed mutant plants with normal plants. In hybrid offspring, plants with excellent traits were selected and then high-yield varieties were selected. Using this new technology, we have successfully cultivated "Superlarge grain" wheat varieties, as well as a range of trait specific wheat breeding materials. This new technology can be used for ultra-high-yield breeding of all crops.

\section{Fund Projects}

Longnan science and technology bureau project, Gansu province. Project number: 2017-04.

\section{References}

[1] Tian Ji chun, Super Wheat and Its Breeding Methods [J]. Journal of Triticeae Crops, 2002, 22 (1): 87-90. 
[2] Li Mei xia, Yang Rui, Li You mei, etc., QTL Mapping of Grain Characteristics of "Zhong13" RIL Population in Polish Wheat X General Wheat Strain "Zhong13" [J]. Journal of Wheat Crops, 2012, 32 (5): 813-819.

[3] Liu Chun guang, Research Prospect of Cytoplasmic Male Sterile Lines in Common Wheat [J]. Discovery of Nature, 1994, 13 (4): 57-61.

[4] Wang Cai ping, Zuo Lian Zhong, Xu Qi, etc. Variation Analysis of RVA Parameters of Generation M2 Induced by Radiation of "Nongda 179" [J]. Journal of Triticeae Crops, 2007, 27 (2): 237-240.

[5] Wu Zhen lu, Fan Zhan Ru, He Zhonghu, et al. A Study on Improving the Breeding Effects of Spring Wheat by Combining Hybridization and Mutation [J]. Journal of Triticeae Crops, 2010, 30 (5): 976-980.

[6] Sun Guang zu, Chen Yi chun, Liu Xinchun, et al. Experience in Breeding Spring Wheat Varieties by Combining Radiation and Hybridization [J]. Atomic energy agriculture application, 1981, (4): 15-21.

[7] Wang Lin qing, Zhang Wei qiang, Fan Qing xia, et al., Discussion on the Effects of Radiation Breeding in Winter Wheat by Combining with Radiation and Hybridization [J]. Acta Agronomica Sinica, 1980, 6 (4): 237-244.
[8] Yang Zhan liang, Preliminary Report on the Development of Frog Eggs Induced by Monochromatic Light [J]. Potential Science, 1990, (4): 26.

[9] Yang Zhan liang, Light and Life, Genes, Species [J]. Bulletin of Biology, 1998, 33 (10): 14-16.

[10] Li Bu liang, Biomolecular Ordering Derived From Gauge Field [J]. Potential Science, 1985, (1): 36.

[11] Han Wei bo, Liu Lu Xiang, Guo hui Jun, et al., New Techniques for Wheat Breeding [J]. Journal of Triticeae Crops, 2005, 25 (6): 125-129.

[12] Yang Zhan Liang, Chu Qiao Xu, Zhang Yi le, et al. Effects of Mutagenesis and Hybridization on Breeding Super High Yield Wheat [J]. Journal of Anhui Agricultural Science, 2015, 43 (18) $37-40$

[13] Yang Zhan liang, Color and Species [J]. Potential Science, 1986 (5): 25

[14] Li Ru qi, Tan jia Zhen, Sheng Zujia, et al. Chinese Encyclopedia of Biology: Genetics [M]. Beijing-Shanghai: Enc yclopaedia of China Publishing House, 1983: 36-37.

[15] Chen Jia hui, Lan Jin hao, Wang Hui, et al. Preliminary QTL Mapping of Grain Morphology and 1000-Grain Weight Traits in Wheat [J]. Journal of Triticeae Crops, 2011, 31 (6): 10011006. 